\title{
A Sustainable Transport System and Travel Choice Adaptation of the Disadvantaged in Hong Kong
}

\author{
Joseph Cho Yam Lau*
}

26E, Block 7, South Horizons, Apleichau, Hong Kong

\begin{abstract}
This paper investigates the interactions between the coping travel behaviour of the disadvantaged and policies for a sustainable transport system in Hong Kong. The concepts of quality of life, a sustainable transport system and coping behaviour are reviewed. The construction of an effective sustainable transport system depends on transport policy makers understanding individual travel behaviour and providing a wide range of adaptation choices to help individuals to overcome mobility constraints. In-depth interviews were conducted in 1996 to ascertain the travel behaviour of the disadvantaged, the results of which indicate that to cope with socio-economic and land-use constraints, the respondents choose opportunities that are in close proximity to living neighbourhoods, taking cheaper slower transport modes and using nonmortorised modes to non-work activities, working women chose employment opportunities that close home to care for children. Some respondents remained in long-term unemployment rather than seeking distant employment to save travel costs. The results should help the government to formulate sustainable transport policies for Hong Kong.
\end{abstract}

Keywords: The disadvantaged, sustainable transport system, adaptation travel behaviour, adaptation choice and transport policy formulation.

\section{INTRODUCTION}

Conventional transport planning in Hong Kong has traditionally been limited to the prediction of travel demand and the provision of an adequate transport infrastructure to alleviate road congestion. Over time, this type of transport planning has induced travel destinations to move farther apart with an associated increase in energy use and air and noise pollution from transport $[1,2]$. In recognition of these problems, some urban transport planners in Hong Kong have moved away from the conventional four-step approach to transport planning to the construction of a sustainable transport system that serves the daily travel needs of the populace without causing great harm to the environment and health of Hong Kong people [3]. To build a sustainable transport system, the focus of transport planning needs to shift from the search for strategies to change behaviour to the search for strategies that provide more choice (more pedestrian facilities for the elderly and cycling lanes to allow individuals to use bicycles for short trips, for example) [4-6]. It is also important to understand the travel behaviour of different social groups so that the transport system can be streamlined to create more sustainable services and improve mobility [6-8]. Based on these concepts, this paper explores a sustainable transport planning approach for Hong Kong.

\section{QUALITY OF LIFE AND SUSTAINABLE TRANS- PORTATION}

Mobility is defined as the ability of people to move or the amount of movement that is required to meet basic needs [9]. Mobility problems are related to quality of life, and can be explained in terms of entitlement theory [10]. Sen [10]

*Address correspondence to this author at the 26E, Block 7, South Horizons, Apleichau, Hong Kong; E-mail: laucya@graduate.hku.hk argues that the achievement of basic needs is determined by initial endowments and production (e.g., growing one's own food) and exchange (e.g., selling one's labour for income and food) entitlements. The failure of these entitlements can occur either because of a decrease in a group's endowment (e.g., the loss of labour power because of old age), or because of an unfavourable shift in the group's exchange entitlement (e.g., the loss of employment or decrease in wages because of mobility constraints). The author postulates that mobility is a capability that is a form of entitlement exchange, and thus loss of employment or isolation from normal social activities because of mobility problems can be regarded as an entitlement failure or a decrease in quality of life $[11,12]$. In this study, the disadvantaged are defined as those who are not capable of the movement required to achieve their basic needs, which may include motorised and non-motorised movement. The disadvantaged include the elderly, the young, lone mothers, the handicapped, lowincome persons, the unemployed and the chronically ill, most of whom are recipients of public assistance [12].

This paper hypothesises that the mobility of the disadvantaged in Hong Kong depends on the interaction between the adaptation choices of individuals and the sustainability of the transport system. Transport systems are important in helping individuals to move about and exchange labour for income, but also constitute one of the main causes of deteriorating air quality, which harms human health. Thus, the development of sustainable transport systems that provide adequate mobility without causing significant harm to the environment is seriously needed, particularly for compact cities such as Hong Kong [13, 14]. Sustainable transportation planning should be built into the framework of sustainable development. The Brundtland Report [15] stresses the necessity to protect the environment while also promoting economic vitality and social equity, which presents a challenge 
in implementing balance among environmental, economic and social sustainability concerns. Sustainable social development should aim to eradicate widespread poverty and hunger, meet basic human needs and address the growing social and economic disparities [16].

The Report states that development should meet the needs of the present generation without compromising the ability of future generations to meet their needs [15]. Based on this concept, Black [17] defines sustainable transportation as that which meets current transport and mobility needs without compromising the ability of future generations to meet these needs. Thus, a sustainable transport system not only limits emissions and waste from transport, but also affords basic access and helps people to meet their development needs. It is affordable and offers individuals a choice of transport modes. Black [14] lists a number of aspects of sustainable transportation, which include mobility services providing access to employment and those for the transport disadvantaged. Localities can increase the mobility levels of their residents by ensuring that transport facilities are available to all members of the community through providing regular urban public transport and specialized public transport for the handicapped and others with mobility problems. Studies have found that the aims of sustainable transport can be achieved more effectively by integrating transport system development with socioeconomic and land-use planning, which involves improving the job-housing balance, discouraging urban sprawl and transforming cities from monocentric to polycentric entities to reduce the movement and car use of workers [18].

\subsection{Socioeconomic and Land-use Variables and Sustain- able Transportation}

Studies in the United States have found that the process of searching for a job takes different forms depending on the jobseeker's social network resources. Roughly half of all jobs are obtained with the assistance of a social contact [19]. Thus, adequate provision of mobility through a sustainable transport system enables low-income workers to contact other people and obtain job information. Ong and Blumenberg [20] find that welfare recipients face a number of obstacles in making the transition from welfare to work, one of which is geographical separation from employment opportunities. They suggest that proximity to low-wage jobs benefits welfare recipients through reduced commuting expenses and increased earnings. Workers with young children, particularly lone parents, have more non-work commutes, which results in time constraints on travelling to employment [21]. In addition, the traditional gender division of labour in a family imposes time conflicts between employment and household duties for working mothers. A study carried out by Tong and Wong [22] in Hong Kong indicates that the labour participation rate of female workers in six remote new towns was $34.6 \%$, approximately two thirds $(67 \%)$ of the total labour participation rate of women in Hong Kong $(51.8 \%)$.

Mobility declines with increasing age, reflecting the onset of physical or mental infirmity, affordability of travel for those on retirement incomes and the mal-design of transport systems and operational arrangements. In their study of spatial mismatch between jobs and employment, Smith and
Zenou [24] find that the unemployed can choose low amounts of search and long-term unemployment if they reside far from jobs. A study by Johansson [25] in Sweden finds that the choice of mode for young children's journeys to organised leisure activities depends on the attitude of their parents towards environmental factors, such as the traffic environment and quality of footpaths; the characteristics of the child, such as age and maturity; and individual parental factors, such as trust and the need to protect the child. To provide basic access and more opportunities for people in need and to reduce the impact of transport on the environment, transport policy makers need to understand the travel and coping behaviour of disadvantaged people [7].

\section{CONCEPT OF ADAPTATION}

Gärling et al. [23] propose that travel behaviour results from the choices that people make according to interdependent and dependent desires or obligations to participate in activities. The ability of individuals to cope with accessibility constraints depends on the travel options that are available in their choice set and the goals that they form over time in response to evaluations of the monetary cost, time and convenience of travel. Travel choices are assumed to be made up of trip chains, which are defined as bundles of trip attributes (purpose or activity, destination, mode, departure and arrival time, travel time and monetary cost) [6]. Socioeconomic and land-use constraints influence the bundles of trip attributes that characterize travel options and influence people's travel behaviour.

After setting a goal of reduced commuting expenses, low-income people form implementation intentions, which entail commitment to a plan for how to attain the goal. Goal achievement is influenced by a variety of factors, including the perception of goal importance, commitment, goal difficulty and information about progress towards the achievement of goals. It is assumed that individuals form a plan to achieve a goal according to a wide range of travel options, constraints and individual factors [26]. The effectiveness of a strategy to cope with accessibility constraints is evaluated by an individual over time on the basis of negative feedback. If such evaluations indicate a goal discrepancy, then more costly changes will be implemented. This application of the cost-minimisation principle of adaptation leads to the formation of a hierarchy of coping strategies [27].

\section{GEOGRAPHIC DISTRIBUTION OF THE DISAD- VANTAGED IN HONG KONG}

Hong Kong is an extremely compact city, with an area of only $1,104 \mathrm{~km}^{2}$ and a population in 2006 of 6.86 million. Hong Kong has experienced the rapid decentralisation of its population from urban areas to outlying new towns, a phenomenon that has led to longer travel work trips from the new towns to the employment centres in the urban areas for $19.6 \%$ of the working population. The spatial mismatch between housing and jobs has had an adverse effect on the development of a sustainable transport system, because the long-distance work trips produce excessive transport emissions $[13,33]$.

The geographical distribution of the major disadvantaged groups in Hong Kong is depicted in Table 1. It shows that the Southern and Eastern districts in Hong Kong Island and 
the Kwun Tong, Wong Tai Sin and Sai Kung districts in Kowloon have a higher percentage of handicapped persons than have the other districts; that is, the handicapped population of the urban areas is higher than that of the new towns [29].

Regarding the young and elderly populations, the author analysed the proportion of the young (aged below 9) and the elderly (aged above 65) population in each district. Table 1 indicates that there is a higher proportion of the young to the total district population in new towns, such as those in the Yuen Long and North districts, where the young accounted for $9.8 \%$ and $8.1 \%$ of the district population, respectively. The elderly population is concentrated in older urban areas, such as the Sham Shui Po, Kwun Tong, Eastern and Wanchai districts [28]. Many of the elderly live apart from their children and are supported by inadequate savings or rely on their children for financial support, with social security allowance as a subsidy [30].

Regarding low-income households (those households that earned less than HK\$6,000 per month or one third of the average in 2006), Table 1 shows that the percentage of these households is high in urban areas including the Sham Shui Po, Kwun Tong and Wong Tai Sin districts. The poorest district in Hong Kong is Sham Shui Po, in which lowincome households accounted for $20.6 \%$ of the population. The percentage of such households in the new towns ranges from $12.0 \%$ to $16.4 \%$ [31].

In $2007,288,145$ households, or about $12.9 \%$ of the total households in Hong Kong, received Comprehensive Social
Security Assistance (CSSA) (a scheme to provide cash assistance for financially vulnerable households to meet their basic needs). The new towns of Yuen Long, Tuen Mun and Kwai Tsing accounted for a high share of such households in 2007 , with $14.4 \%, 8.0 \%$ and $9.2 \%$ of the total single parent CSSA cases, respectively, while the poor urban districts of Kwun Tong and Sham Shui Po accounted for 10.8\% and $7.9 \%$ of such cases, respectively $[29,38]$.

The geographical distribution of the disadvantaged groups shows that the proportion of the handicapped, elderly and low-income populations in the individual district populations is high in the urban areas (Fig. 1 and Table 1). Also, between 1996 and 2006, the average monthly household income in Hong Kong was almost constant, whereas the share of low-income households increased significantly. For example, the share of low-income households in the populations of the Tuen Mun and Kwun Tong districts increased by $6.6 \%$ and $6.3 \%$, respectively $[32,38]$.

\section{THE CHANGING TRANSPORT SYSTEM IN HONG KONG}

In the 1970s and 1980s, the Kowloon-Canton Railway (KCR) was built in Hong Kong to cater for people travelling from the new towns, and the Mass Transit Railway (MTR) was built in urban areas to serve daily travel needs. The merger in December 2007 between the two railway operators of these lines allowed Mass Transit Railways Corporation Limited (MTRCL) to take over the operation of the Kowloon-Canton Railways networks and combine the fare system of the two networks [37]. The MTRCL operates nine

Table 1. Distribution of the Disadvantaged By Hong Kong District, $2007 *[28,31] * *[29]$

\begin{tabular}{|c|c|c|c|c|}
\hline District & *The Young (\%) & *The Elderly (\%) & $* *$ The Handicapped (\%) & *Household Income $<$ HK\$6,000/Month \\
\hline Yuen Long new town & $9.8 \%$ & $8.3 \%$ & $1.3 \%$ & $15.0 \%$ \\
\hline Tuen Mun new town & $7.5 \%$ & $8.8 \%$ & $1.6 \%$ & $15.0 \%$ \\
\hline Tai Po new town & $6.8 \%$ & $9.5 \%$ & $1.9 \%$ & $14.3 \%$ \\
\hline North New Territories & $8.1 \%$ & $10.1 \%$ & $1.7 \%$ & $15.6 \%$ \\
\hline Tsuen Wan new town & $8.4 \%$ & $11.5 \%$ & $1.5 \%$ & $12.6 \%$ \\
\hline Kwai Tsing new town & $7.4 \%$ & $13.9 \%$ & $1.8 \%$ & $16.4 \%$ \\
\hline Sha Tin new town & $7.1 \%$ & $10.3 \%$ & $1.8 \%$ & $12.0 \%$ \\
\hline Sham Shui Po (Kowloon) & $7.0 \%$ & $16.7 \%$ & $1.9 \%$ & $20.6 \%$ \\
\hline Kowloon City (Kowloon) & $7.4 \%$ & $14.4 \%$ & $1.8 \%$ & $13.7 \%$ \\
\hline Yau Tsim Mong (Kowloon) & $7.2 \%$ & $13.3 \%$ & $1.5 \%$ & $15.6 \%$ \\
\hline Kwun Tong (Kowloon) & $7.4 \%$ & $16.0 \%$ & $2.0 \%$ & $18.5 \%$ \\
\hline Wong Tai Sin (Kowloon) & $6.6 \%$ & $17.8 \%$ & $2.1 \%$ & $18.9 \%$ \\
\hline Sai Kung (Kowloon) & $9.0 \%$ & $8.2 \%$ & $1.3 \%$ & $9.9 \%$ \\
\hline Eastern (H. K. Island) & $6.9 \%$ & $14.1 \%$ & $2.0 \%$ & $12.6 \%$ \\
\hline Wan Chai (H.K. Island) & $6.3 \%$ & $14.5 \%$ & $1.5 \%$ & $11.4 \%$ \\
\hline Central and Western (HK Is.) & $7.7 \%$ & $12.4 \%$ & $1.6 \%$ & $10.8 \%$ \\
\hline Islands & $10.4 \%$ & $8.8 \%$ & $1.1 \%$ & $15.0 \%$ \\
\hline Southern (H.K. Island) & $7.6 \%$ & $13.5 \%$ & $2.4 \%$ & $11.8 \%$ \\
\hline Whole Territory & $7.7 \%$ & $12.4 \%$ & $1.8 \%$ & $14.7 \%$ \\
\hline
\end{tabular}




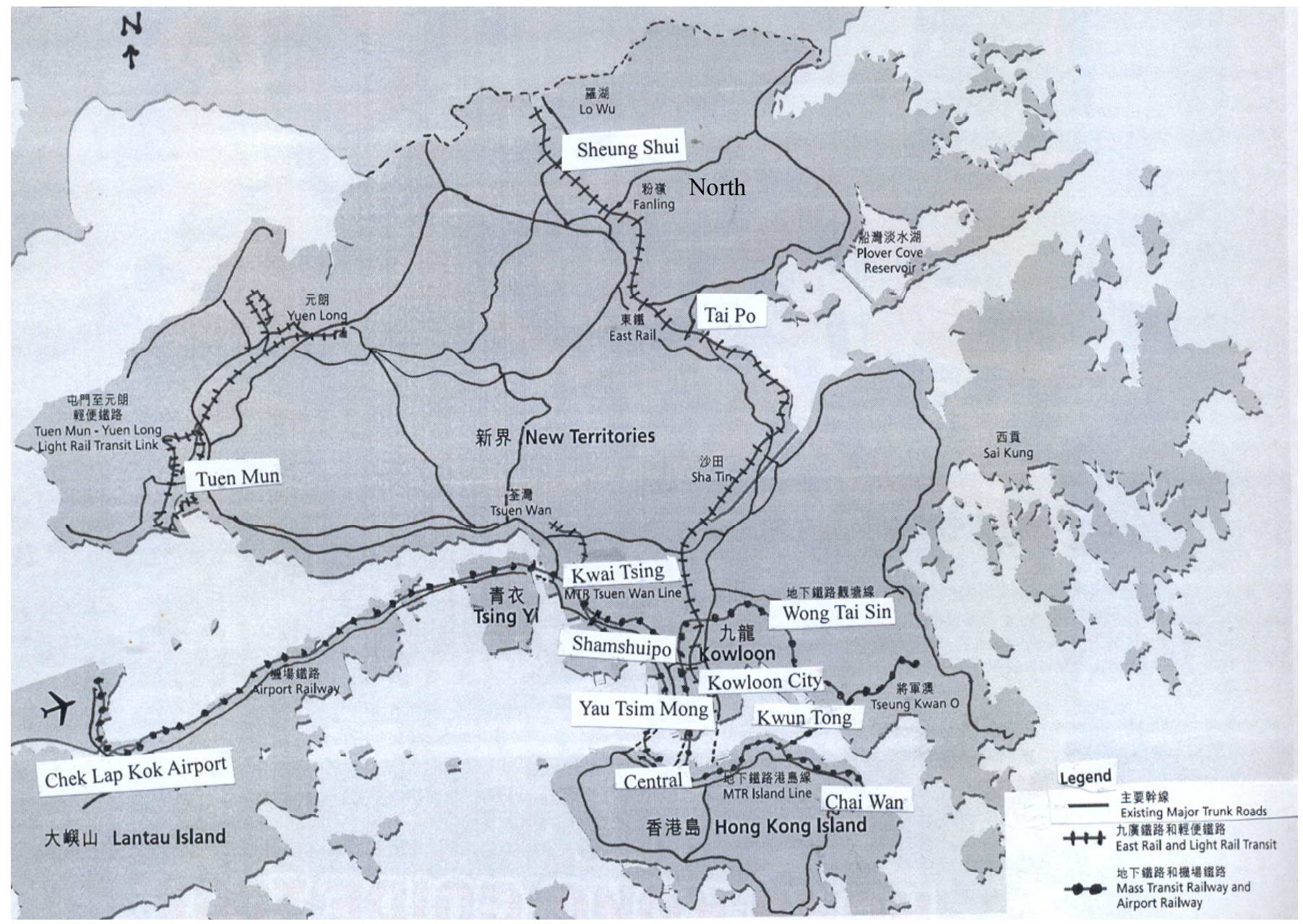

Fig. (1). The transport system in Hong Kong and seven urban districts [6].

main rail networks, including four underground rail lines in the urban areas and new town of Tsueng Kwan O; the East Rail and Ma On Shan Light Rail, which provide services in the eastern New Territories; the West Rail, which is supplemented by the Light Rail, providing services in the northwestern New Territories; and the Airport Express line, which links the new airport and new town of Tung Chung to the city centre (Fig. 1).

In 2006, public buses accounted for $35.7 \%$ of daily work trips, the MTR and KCR for $29.9 \%$, private cars for $6.3 \%$ and walking for $11.1 \%$. This means that over $90 \%$ of the daily work trips in Hong Kong are made using public transport [35]. Hong Kong transport planning is based on the conventional four-step transport approach, which predicts the demand of motorised vehicles and seeks to provide an adequate transport infrastructure to meet this demand. This planning approach, however, gives rise to a greater volume of motorised traffic, which increases air and noise pollution. Such increases in traffic also make pedestrians feel unsafe when walking to nearby activities $[1,13]$. Hong Kong suffers from serious air quality problems at the street level as a result of the high volume of traffic (Fig. 2). The Hong Kong government needs therefore to develop effective sustainable development policies to minimise vehicle trips in urban areas to create a more sustainable and amenable environment for pedestrians [36].
From 1992 to 2002, the average individual's daily trip rates to home-based work and home-based social and recreation activities dropped from 1.42 and 0.61 to 1.40 and 0.57 , respectively. The reduction in the trip rates for work and non-work activities has been attributed to the economic downturn and an increase in poverty [34].

\section{METHODOLOGY}

In 1996, in-depth interviews were conducted to investigate the mobility constraints of the disadvantaged in Hong Kong, the findings of which formed the basis of the author's Master degree thesis [12]. The author interviewed 40 respondents, including lone mothers, the young, the elderly, the unemployed, low-income workers and the handicapped, most of whom received some form of social assistance. A pseudonym was given to each of the interviewees to keep his or her identity confidential.

\subsection{Choice of Slower or Non-Motorised Transport Modes to Cope with Financial Constraints}

Most low-income workers take efficient and fast public transport modes, such as the MTR, for employment trips. Regarding non-work activities, some low-income people take slower and cheaper transport modes to reduce transport expenses or because there is inadequate public transport service in their neighbourhood of residence. Walking is the 


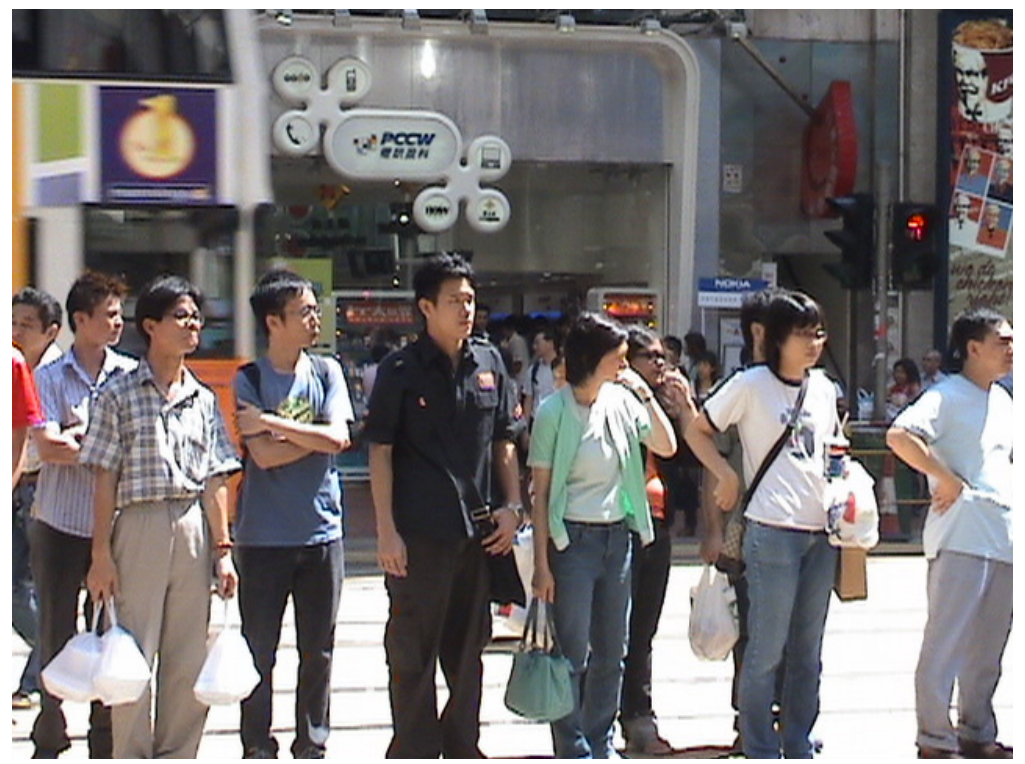

Fig. (2). A pedestrian uses her hand to keep out polluted air while crossing a main road in causeway bay.

main transport mode in Hong Kong for the poor to reach various non-work destinations, and includes escorting children to nearby schools or buying food from markets in nearby districts. These kinds of travel coping behaviour result in longer travel times and reduce the amount of time spent on other basic need activities. For example, one respondent escorted her two children to school every day on foot, had to stay near the school for several hours and then take her children back home. Some respondents said that their children, who had to walk long distances to school, always felt exhausted and could not concentrate on their school lessons. Apart from school trips, low-income people attend a wide range of non-work activities, such as meeting friends and participating in social gatherings, on foot. The coping behaviour of reaching activities on foot limits the range of activities of low-income people to the neighbourhoods in which they live, which leads to shrinking social networks. Also, as noted, air pollution is very serious on the streets in the urban areas of Hong Kong, and walking is unpleasant, congested and generally hazardous as a result of the deteriorating pedestrian environment (see Fig. 2).

To cope with higher food prices in their own neighbourhoods, some low-income people travel to nearby districts, where food is cheaper, to buy groceries. For example, on Hong Kong Island, the variety and price of food in Shaukeiwan is greater and lower, respectively, than in other nearby districts; as a result, low-income people will take the tram from Causeway Bay or North Point to Shaukeiwan to buy foodstuffs. Certainly, the saving on food prices covers the expense of travelling between two districts. Hong Kong's good public transport network and compact land-use structure allow residents, especially those in remote new towns, to adopt this strategy to save daily expenses on foods.

\subsection{Choice of Activity Opportunities and Transport Modes of Lone Parents and the Elderly}

Some low-income people in Hong Kong, particularly lone parents, feel that they are unable to pay high travel expenses and have inadequate time to perform household duties. To cope with the time conflict between employment and household duties, they tend to develop family support networks and live near their workplaces. For example, one interviewee was a working lone mother who lived with her parents in Yau Tsim Mong District, which was near her place of work. As her mother helped to look after her child, she had the opportunity and time to work (see Fig. 1).

To cope with social isolation, some of the handicapped develop their social networks by visiting nearby recreation parks on foot. For example, one respondent had chronic osteoarthritis (a form of arthritis that is characterised by the chronic degeneration of the cartilage of the joints), which made him dependent on a cane to walk. Every day, he limped with great difficulty down a long slope from his home to a nearby park in Chai Wan District to meet his friends, who would help him when he faced illness or family problems. Because his condition did not allow him to climb slopes, he had to take a public bus home in the evening. Adequate provision of public transport services, such as the MTR and buses, which are accessible to the handicapped, is important to increase the ability of this population to move about and reduce their social isolation.

The elderly experience impaired eyesight and cannot see well at night because of dim streetlights. To cope with this, they choose not to take public transport modes that do not provide easy access for the elderly. Instead, they take slower public transport modes, such as buses or trams, to basic need activities, such as visiting medical specialists. Elderly people fear that the tunnels in the MTR system are too complicated for them, that they will not be able to find the exit or that the congested and fast-moving crowds in the MTR stations might push them to the ground, which could result in dangerous consequences.

\subsection{Reduction in the Frequency of Travelling to Activi- ties to Cope with Financial Constraints and Physical Dis- ability}

One of the strategies of low-income people to cope with high transport expenses is to reduce their frequency of travelling to non-work activities. They limit their participation in 
recreational and social activities to cut transport fares and expenses such as buying gifts for social gatherings. Sometimes, they avoid participating in social activities because they do not want their relatives or friends to pay for the whole share of activity expenses, which makes them feel embarrassed. In addition, the relatives of low-income people sometimes avoid seeing them because they fear that their poorer relatives will ask to borrow money from them. This coping behaviour results in the exclusion of the latter from the social activities that are customary in Hong Kong society. This travel coping behaviour not only results in serious damage to the social network development of poor households but also negatively influences the young in these families, who need to play with new friends and explore new environments to sustain healthy social and physiological growth.

The mobility of handicapped children is seriously hindered by the traditional Chinese belief that the parents of these children might have done something wrong and that God has punished them by giving them a disabled child. To avoid feeling embarrassment, many parents of the handicapped avoid bringing their children out with them to social activities. For example, the parents of a young blind respondent disliked taking their child out because they felt embarrassed about having a blind child and the child had difficulty moving around by himself. Those handicapped children who receive inadequate parental or social support are usually excluded from participating in the activities that are usually enjoyed by other children in Hong Kong, such as attending school and playing in playgrounds.

\subsection{Choice of Long-term Unemployment to Cope with Unaffordable Long Work Trips}

Low-income workers in remote new towns with secure employment in an urban area experience long travel times and pay high public transport fares for their daily work trips. To cope with this spatial mismatch between jobs and housing, some of them choose long-term unemployment or do little to find a job. For example, a male respondent said, "I think that there are good job opportunities and wages in the urban areas, but I would still prefer a job in Tuen Mun (a new town) because the travel costs from Tuen Mun to the urban areas are too expensive for me" (see Fig. 1). The time conflict produced by the spatial mismatch has serious impacts on lone parents in the remote new towns, who have to take care of their children and secure full-time work to earn adequate money to sustain a certain level of quality of life of their family members. For example, a single parent respondent said, "As my son has asthma, I have to take him to hospitals in Kowloon from time to time. These long-distance trips (from Sheung Shui, a new town, to an urban area) consume a lot of my income. My health is also affected by travelling between hospitals". To cope with this accessibility problem, some low-income workers quit their jobs or seek part-time work and receive CSSA so that they can spend more time taking care of their children. Some mature new towns, such as Tuen Mun and Yuen Long, have now been developed into employment sub-centres, and many workers can secure employment in these sub-centres. However, some middle-aged respondents found that employers prefer to employ young employees and discriminate against middle-aged workers. Also, some of the respondents are former manufac- turing workers and their skills became redundant when the structure of the economy changed from manufacturing to service industries. Consequently, many of them have demonstrated coping behaviour in the form of long-term employment and are CSSA recipients.

The empirical evidence suggests that the adaptation choice set of the disadvantaged includes four kinds of coping strategies: choosing cheaper, slower transport modes instead of taking public transport to non-work activities, selecting social opportunities that are close to the neighbourhood of residence, reducing the frequency of travel to non-work activities to save money on travel, and remaining unemployed rather than seeking distant employment to save travel costs (money and time). As sustainable transport planning aims to increase the mobility of the disadvantaged to meet basic needs without compromising the mobility of future generation to meet their basic needs [17], transport planning in Hong Kong should improve the mobility of the former by providing more transport mode choices and affordable public transport services for the poor and the handicapped. Furthermore, the ability of the poor to move about freely can be improved if the pedestrian environment is safe and pollution free. Improvement of the social support networks of lone parents, such as childcare services, could improve their chances to secure employment and improve their quality of life. The following section discusses these aspects in greater detail.

\section{IMPLICATIONS FOR THE DEVELOPMENT OF A SUSTAINABLE TRANSPORT SYSTEM}

The results of the interviews confirmed that the mobility of individuals in Hong Kong depends on the effectiveness of the transport system in providing a wider range of choices for individuals to include in their choice sets so that when faced with travel constraints, they have more choice in developing coping strategies. This paper therefore proposes the following socioeconomic and land-use policies to develop a sustainable transport system in Hong Kong.

First, government decision makers should expand childcare services for working parents to allow them more time to work. Social services for the handicapped in terms of transportation provision, education and social contact should be strengthened and upgraded to the levels that are currently enjoyed by mainstream society. Hong Kong policy makers should also seek to strengthen traditional family support networks by encouraging children to live near their elderly parents, ideally in the same neighbourhood, so that they can help each other with mobility problems. The government should set up job information offices in the new towns to provide first-hand job information to residents, especially new immigrants and unskilled workers.

Second, the Hong Kong government should directly subsidise public transport fares for low-income workers who live in remote areas to help them to secure employment. Policy makers should also improve the mobility of workers by providing a range of public transport services, improving the coordination between public transport modes to shorten the time spent on transfers, developing an environmentally friendly railway system as the backbone of the public transport system and restricting motor vehicles in urban areas by imposing congestion charge schemes. Public transport serv- 
ices should be accessible to the handicapped and partially or fully subsidised for the daily work and school trips of this population. New investment in transport infrastructure should be put into building networks to connect the new towns to employment sub-centres in the New Territories to provide more opportunities for poor workers in the new towns to seek jobs that are close to their neighbourhood of residence.

Finally, pedestrian facilities, in addition to being environmentally friendly, are important for people with low incomes to reach activities. In many street networks, such as the market streets in the older urban areas, motor and goods vehicles should be banned to promote safety and enhance pedestrian movement and convenience. Other initiatives such as a bike-and-ride scheme (the combined use of a bicycle and public transport in a single trip) should be promoted in the more densely populated urban areas [5]. Government decision makers should build more covered walkways, brightly lit walking routes, ramps and elevated pedestrian facilities to separate traffic and pedestrians, and construct more outdoor covered escalators along steeply sloping streets in hillside housing neighbourhoods, such as Kwun Tong and Wong Tai Sin, to help the elderly to reach social and recreation facilities.

\section{CONCLUSION}

This paper investigates the relationship between individual travel behaviour and a sustainable transport system for Hong Kong. The interview study indicates that the disadvantaged develop different types of travel coping behaviour, but that most of their strategies actually exclude them from participating in basic activities, such as social gatherings and employment, because they are unable to afford the time and money that is involved in travelling to such activities. The survey results confirm the hypothesis that the mobility of individuals in Hong Kong is the product of their adaptive choices and the availability of a sustainable transport system. The capacity of the interview respondents to cope with travel constraints was based on the adaptation choices that were available in their choice set, which were fewer than those enjoyed by more advantaged people. To build a sustainable transport system, the government should develop strategies that enhance personal mobility by providing more travel choices for the disadvantaged. The first step to improving the capacity of the disadvantaged to cope with mobility constraints is to understand and be responsive to the travel behaviour of all of the stakeholders in the transport system. As the function of the transport system in Hong Kong is to facilitate the movement of the populace, during the process of transport policy formulation the bodies that are responsible for transport governance should behave more democratically by including not only conventional committees or institutions in their planning, but also mechanisms for different social groups and transport users to express their views on the construction of a sustainable transport system. In addition, future transport policies should be integrated with other policies related to socioeconomic and land-use development to improve their effectiveness in enhancing individual mobility.

\section{REFERENCES}

[1] Hong Kong Transport Department, Third Comprehensive Transport Study: Technical Report - Appendices Volume 1, Hong Kong SAR: Wilbur Smith Associates Limited, 1999.

[2] S. Owens, "From 'predict and provide' to 'predict and prevent'? pricing and planning in transport policy", Transport. Pol., vol. 2 (1), pp. 43-50, 1995.

[3] Legislative Council, Wan Chai Development Phase II Review Harbour-front Enhancement Review - Wan Chai, Causeway Bay and Adjoining Areas Outcome of Public Engagement at the Envisioning Stage, Panel on Planning, Lands and Works, File Number: CB(1)1519/05-06(03), Hong Kong SAR, 2006.

[4] S. Handy, "Methodologies for exploring the link between urban form and travel behaviour", Transport. Res. D., vol. 1(2), pp. 151$165,1996$.

[5] K. Martens, "The bicycle as a feedering mode: experiences from three European countries", Transport. Res. D., vol. 9, pp. 281-294, 2004.

[6] J.C.Y. Lau and C.C. H. Chiu, "Accessibility of workers in a compact city: the case of Hong Kong", Habitat. Int., vol. 28, pp. 89102, 2004.

[7] J.C.Y. Lau, "Accessibility and the coping behaviour of the nonemployed people in Hong Kong", Habitat. Int., vol. 30, pp. 1047$1055,2006$.

[8] I. Salomon and P.L. Mokhtarian, "Coping with congestion: understanding the gap between policy assumptions and behaviour", Transport. Res. D., vol. 2 (2) pp. 107-123, 1997.

[9] T. Litman, "Measuring transportation: traffic, mobility and accessibility", Inst. Transport. Eng. J., vol. 73 (10), pp. 28-32, 2003.

[10] A. Sen, Poverty and Famines, Clarendon: Oxford, 1981.

[11] J. Preston and F. Rajé, "Accessibility, mobility and transportrelated social exclusion", J. Transport. Geogr., vol. 15, pp. 151$160,2007$.

[12] J.C.Y. Lau, "Evaluating the performance of public transport operations in Hong Kong from the point of view of the disadvantaged", Unpublished M. Phil. Thesis, University of Hong Kong, Hong Kong SAR, 1997.

[13] B. P. Y. Loo and A. S. Y. Chow, "Changing urban form in Hong Kong: what are the challenges on sustainable transportation?" Int. J. Sustainable. Transport., vol. 2, pp.177-193, 2008.

[14] W.R. Black, "Sustainable Transport: Definitions and Responses", in Conference Proceeding 37: Integrating Sustainability into the Transportation Planning Process, Washington: Transportation Research Board, 2005, pp. 35-43.

[15] United Nations World Commission on Environment and Development. Our Common Future (The Brundtland Report). Oxford: Oxford University Press, 1987.

[16] E.E. Boschmann and M.P. Kwan, "Toward socially sustainable urban transportation: progress and potentials", Int. J. Sustainable. Transport., vol. 2, pp. 138-157, 2008.

[17] W.R. Black, "Sustainable transportation: A US perspective", $J$. Transp. Geogr., vol. 4 (3), pp.151-159, 1996.

[18] M. Janic, "Sustainable transport in the European Union: A review of the past research and future ideas", Transp. Rev., vol. 26 (1), pp. 81-104, 2006.

[19] K. Chapple, "Overcoming mismatch: beyond dispersal, mobility, and development strategies", J. Am. Plan. Assoc., vol. 72 (3), pp. 322-337, 2006.

[20] P. Ong and E. Blumenberg, "Job access, commute and travel burden among welfare recipients”, Urban. Stud., vol. 35(1), pp. 77-93, 1998.

[21] A. J. Khattak and D. Rodriguez, "Travel Behaviour in NeoTraditional Neighbourhood Developments: A Case Study in U.S.A.”, Transport. Res. A., vol. 39 (6), pp. 481-500, 2005.

[22] R. Tong and H. Wong, The poverty and working situation of women in remote areas, Hong Kong SAR: Civic Party, 2007.

[23] T. Gärling, D. Eek and P. Loukopoulo, "A conceptual analysis of the impact of travel demand management on private car use", Transp. Pol., vol. 9, pp. 59-70, 2002.

[24] T.E. Smith and Y. Zenou, "Spatial mismatch, search effort, and urban spatial structure", J. Urban. Econ., vol. 54, pp. 129-156, 2003.

[25] M. Johansson, "Environment and parental factors as determinants of mode for children's leisure travel", J. Environ. Psychol., vol. 26 (2), pp.156-169, 2006. 
[26] P. Loukoupoulous, C. Jakobsson, T. Gârling, S. Meland and S. Fujii, "Understanding the process of adaptation to car-use reduction goals", Transport. Res. F., vol. 9, pp. 115-127, 2006.

[27] T. Gärling and S. Fujii, "Structural equation modeling of determinants of implementation intentions", Scand. J. Psychol., vol. 43, pp. 1-8, 2002.

[28] Hong Kong Census and Statistics Department, 2006 Population By-Census: Basic Tables for District Council Districts, Hong Kong SAR, 2007.

[29] Hong Kong Social Welfare Department, Physical Disability and Mental Disability: Persons under Social Security Allowance Scheme by Geographical District, December, Hong Kong SAR, 2007. [E book] available: http://www.swd.gov.hk/en/index/site distr [accessed Sept 20, 2008].

[30] Hong Kong Social Welfare Department, Comprehensive Social Security Assistance Cases by Geographical District, Hong Kong SAR, 2007. [E book] available: http://www.swd.gov.hk/en/index/ site distr [Accessed Sept 20, 2008].
[31] Hong Kong Census and Statistics Department, "2006 Population By-Census: Summary Results”, Hong Kong SAR, 2007.

[32] Hong Kong Census and Statistics Department, 1996 Population By-Census: Main Tables, Hong Kong SAR, 1997.

[33] B. Barron, K.W. Ng, C. Lok and R. Gilbert, Sustainable Transport in Hong Kong: Directions and Opportunities, Hong Kong SAR: Civic Exchange and the Asia Foundation, 2002.

[34] Hong Kong Transport Department, "Travel Characteristics Survey 2002: Final Report”, Hong Kong SAR, 2003.

[35] Hong Kong Commission on Poverty, Income Distribution of Hong Kong and the Gini Coefficient by the Government Economist, Hong Kong SAR, 2007.

[36] Hong Kong Census and Statistics Department, 2006 Population By-Census: Main Tables, Hong Kong SAR, 2007.

[37] Legislative Council, Subcommittee on Rail Merger Ordinance Notice, LC Paper No. CB (1)209/07-08, Hong Kong SAR, 2007.

[38] Hong Kong Census and Statistics Department, 2006 Population By-Census: Main Report, Hong Kong SAR, vol. 1, 2007.

(C) Joseph Cho Yam Lau; Licensee Bentham Open.

This is an open access article licensed under the terms of the Creative Commons Attribution Non-Commercial License (http://creativecommons.org/licenses/by$\mathrm{nc} / 3.0 / /$ / which permits unrestricted, non-commercial use, distribution and reproduction in any medium, provided the work is properly cited. 